\title{
Effects of Age on Esophageal Motility: Use of High-resolution Esophageal Impedance Manometry
}

\author{
Young Kwang Shim, ${ }^{1}$ Nayoung Kim, ${ }^{1,2 *}$ Yo Han Park, ${ }^{1}$ Jong-Chan Lee, ${ }^{1}$ Jihee Sung, ${ }^{1}$ Yoon Jin Choi, ${ }^{1}$ Hyuk Yoon, ${ }^{1}$ Cheol Min Shin, ${ }^{1}$ \\ Young Soo Park, ${ }^{1}$ and Dong Ho Lee ${ }^{1,2}$ \\ ${ }^{I}$ Department of Internal Medicine, Seoul National University Bundang Hospital, Seongnam, Gyeonggi-do, Korea; and ${ }^{2}$ Department of Internal \\ Medicine and Liver Research Institute, Seoul National University College of Medicine and Liver Research Institute, Seoul, Korea
}

\section{Background/Aims}

Disturbances of esophageal motility have been reported to be more frequent the aged population. However, the physiology of disturbances in esophageal motility during aging is unclear. The aim of this study was to evaluate the effects of age on esophageal motility using high-resolution esophageal impedance manometry (HRIM).

\section{Methods}

Esophageal motor function of 268 subjects were measured using HRIM in 3 age groups, $<40$ years (Group $A, n=32$ ), 40-65 years (Group B, $n=185$ ), and $>65$ years (Group C, $n=62$ ). Lower esophageal sphincter (LES) and upper esophageal sphincter (UES) pressures, integrated relaxation pressure, distal contractile integral, contractile front velocity, distal latency, and pressures and duration of contraction on 4 positions along the esophagus, and complete bolus transit were measured.

\section{Results}

Basal UES pressure was lower in Group C $(P<0.001)$ but there was no significant difference in the LES pressure among groups. Contractile duration on position $3(10 \mathrm{~cm}$ from proximal LES high pressure zone) was longer in Group $C(P=0.001)$, and the contractile amplitude on position 4 ( $5 \mathrm{~cm}$ from proximal LES high pressure zone) was lower in Group $C(P=0.005)$. Distal contractile integral was lower in Group C $(P=0.037)$. Contractile front velocity $(P=0.015)$ and the onset velocity $(P=0.040)$ was lower in Group C. There was no significant difference in impedance values.

\section{Conclusions}

The decrease of UES pressure, distal esophageal motility, and peristaltic velocity might be related with esophageal symptoms in the aged population.

(J Neurogastroenterol Motil 2017;23:229-236)

\section{Key Words}

Aging; Esophageal motility; Manometry

Received: June 26, 2016 Revised: December 19, 2016 Accepted: January 15, 2017

(a) This is an Open Access article distributed under the terms of the Creative Commons Attribution Non-Commercial License (http://creativecommons. org/licenses/by-nc/4.0) which permits unrestricted non-commercial use, distribution, and reproduction in any medium, provided the original work is properly cited.

${ }^{*}$ Correspondence: Nayoung Kim, MD Department of Internal Medicine, Seoul National University Bundang Hospital, 82, Gumi-ro 173 Beon-gil, Bundang-gu, Seongnam, Gyeonggi-do 13620, Korea

Tel: +82-31-787-7008, Fax: +82-31-787-4051, E-mail: nayoungkim49@empas.com 
esophageal motility using HRIM.

\section{Introduction}

Advances in medical therapy have continuously increased the life expectancy and the effects of age on health are important issues today. Several studies have shown that gastroenterological dysfunction is associated with aging. It was reported that $87 \%$ of residential care clients who are predominantly elderly had a symptom of dysphagia with mealtime difficulties which is associated with gastroenterological dysfunction. ${ }^{1}$ The rate of disordered swallowing was higher in the aged population. ${ }^{2,3}$ Several studies showed decreased sphincter relaxations and decreased esophageal contraction and dilatation in the aged people. ${ }^{4-6}$ The neural control of gastrointestinal function, including esophageal motility is related to enteric neurons. ${ }^{7,8}$ It has been shown that changes in esophageal physiology is associated with loss of esophageal myenteric plexus neurons, which are part of the enteric nervous system (ENS) and lie within the smooth muscle layers of the esophageal wall in the aged population. ${ }^{9-11}$ In addition, underlying disease (such as diabetes mellitus) conditions which is more prevalent in aged people could cause decrease of esophageal motility. ${ }^{12}$ These conditions could be further aggravated by anxiety, depression, malnutrition, and aspiration pneumonia which are frequently found in the aged population. ${ }^{13}$

In the esophagus the anatomy is different from the other hollow viscus. The neural controls and muscles of the proximal part of the esophageal body differ from the distal part of the esophageal body. ${ }^{14}$ That is, the proximal half of the esophagus was built up of both muscle types with predominance of striated muscle, whereas the distal part consists of smooth muscle only. ${ }^{14}$ Thus the effect of aging could be different from other hollow viscus. High-resolution impedance esophageal manometry (HRIM) is a test to assess esophageal motility. HRIM allows visualization of esophageal contractility as a continuum of pressure and time, and has the ability to perform simultaneous impedance testing during manometry examination. Impedance testing is a catheter-based method of assessing bolus movement within the esophagus. When combined with manometry, it provides simultaneous data on bolus transit and contractions to identify whether a functional defect is present. ${ }^{15}$ Compared to conventional manometry, HRIM has greater efficiency, higher quality recordings, and more objective interpretation, ${ }^{15}$ which might help to evaluate change of the proximal and distal part of esophagus during aging.

From this background we hypothesized that esophageal motility would be decreased with ageing, which could be more clearly evaluated by HRIM, and aim to evaluate the effects of age on

\section{Materials and Methods}

\section{Subjects}

Subjects were tested with HRIM between October 2011 and July 2016 at Seoul National University Bundang Hospital were retrospectively enrolled and analyzed. Among the 608 subjects who were tested with HRIM, 340 subjects fulfilled the exclusion criteria, such as history of esophageal or gastric malignancy and surgery or procedure which influences esophageal motility, including pneumatic dilatation or laparoscopic Heller's myotomy, diagnosis of esophageal motility disorder including Nutcracker esophagus, Jackhammer esophagus, achalasia, diffuse esophageal spasm, and scleroderma. Any subjects with EGJ outflow obstruction and major disorders of peristalsis according to the 3.0 Chicago classification of esophageal motility were also excluded from this study. Finally, 277 subjects were enrolled and analyzed. Subjects were divided into 3 groups according to age: 32 subjects (11.5\%) in Group A (below 40 years old), 185 subjects (66.3\%) in Group B (40-65 years old), and 62 subjects $(22.2 \%$ ) in Group C (over 65 years old). The main symptom before HRIM was analyzed depending on the 3 age groups based on electrical medical recording and HRIM reports. Symptoms were categorized as globus, hoarseness, cough, voice change, heartburn, dysphagia, sore throat, dyspepsia, and respiratory difficulty. The premedication history which could be associated with esophageal motility was checked for all subjects within one week before the HRIM test. A study by Mittal et $\mathrm{al}^{16}$ described that an opioid intravenous bolus significantly decreased low esophageal sphincter pressure which may have opiate receptors. Thus premedication history before manometry was checked including opioid medication. This study was approved by the institutional review board of Seoul National University Bundang Hospital (IRB No. B-1506-304-104).

\section{High-resolution Impedance Manometry}

An HRIM with 32 solid state circumferential pressure sensors that are spaced at $1 \mathrm{~cm}$ intervals and 16 impedance sensors (InSIGHT HRiM system, Sandhill Scientific, Highlands Ranch, CO, USA) were used. HRIM assembly was passed transnasally and positioned in order to record from the hypopharynx to the stomach. Studies were performed with the patient in the sitting position after at least 6 hours of fasting. The values of the Chicago classification parameters can be affected by the position of the subjects 
with esophageal hypomotility. All values of this study were evaluated in only the sitting position. The manometric protocol included a 5 -minute period to assess the basal sphincter pressure and 10 liquid $(5 \mathrm{~mL})$ and 10 viscous $(5 \mathrm{~mL})$ swallows. Manometric data were analyzed using the Bio View analysis software. Pressure readings were converted into topographic (color contour) plots to provide a continuous picture of the pressure throughout the segment considered, and impedance testing was performed simultaneously with manometry examination.

\section{Data Analysis}

Data were analyzed using the dedicated Bio View analysis software and the isobaric contour tool was set on $30 \mathrm{mmHg}$ to measure the contractile front velocity $(\mathrm{CFV})$ at the proximal and the distal margins of the distal esophageal segment. Distal latency (DL) was defined as the interval between the upper esophageal sphincter (UES) relaxation and the contractile deceleration point (the inflection point along the $30 \mathrm{mmHg}$ isobaric contour where propagation velocity slows demarcating the tubular esophagus from the phrenic ampulla). The distal contractile integral (DCI) was an integrated calculation, which includes the length, contractile vigor, and duration of contraction in the smooth muscle segment of the esophagus at the $20 \mathrm{mmHg}$ isobaric contour. ${ }^{17-19}$ Integrated relaxation pressures (IRP) were measured as the mean EGJ pressure measured with an electronic equivalent of a sleeve sensor for 4 contiguous or non-contiguous seconds of relaxation in the 10 second window fol-

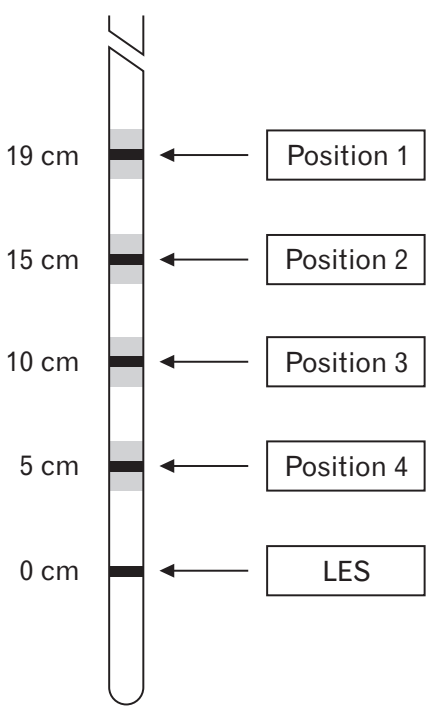

Figure 1. Contractile amplitude and duration at $5 \mathrm{~cm}$ (position 4), 10 $\mathrm{cm}$ (position 3), $15 \mathrm{~cm}$ (position 2), and $19 \mathrm{~cm}$ (position 1) above the proximal lower esophageal sphincter (LES) high-pressure zone. lowing deglutitive UES relaxation. ${ }^{17-19} \mathrm{CFV}$, DL, DCI, and IRP were expressed as the average of 10 liquid swallows. Measurement of LES relaxation pressure, resting pressure, and length, as well as UES pressures, were automatically performed using analysis software, after manual inspection and correction of placement of dedicated markers. Contractile amplitude and contractile duration was measured on position 1 (19 cm from proximal LES high pressure zone), position 2 (15 cm from proximal LES high pressure zone), position 3 (10 $\mathrm{cm}$ from proximal LES high pressure zone), and position 4 ( $5 \mathrm{~cm}$ from proximal LES high pressure zone) (Fig. 1). The beginning of pharyngeal contraction to the beginning of UES relaxation, beginning of pharyngeal contraction to the nadir of UES relaxation, beginning of pharyngeal contraction to the end of UES relaxation, peak pressure of the pharynx to beginning of UES relaxation, peak pressure of the pharynx to nadir of UES relaxation, peak pressure of pharynx to the end of UES relaxation, end of pharyngeal contraction to the beginning of UES relaxation, end of pharyngeal contraction to the nadir of UES relaxation, and end of pharyngeal contraction to the end of UES relaxation were measured for evaluation of UES coordination.

Impedance flow analysis was done for liquid and viscous swallows. Impedance characteristics included: (1) total bolus transit time, as the time interval between bolus entry in the proximal channel and bolus exit in the most distal channel; (2) complete bolus transit, as percentage of waves which had complete bolus transit.

\section{Statistical Methods}

All data are presented as mean \pm standard deviation. Categorical variables are presented as numbers and percentages. ANOVA and post hoc Scheffé tests were used to compare the mean values of manometric parameters and clinical variables among the 3 groups. The chi-square test or Fisher's exact test was used to compare categorical variables among the 3 groups. $P$-values of less than 0.05 were considered statistically significant. All statistical analyses were performed using SPSS software (version 20.0; IBM Corp, Armonk, NY, USA).

\section{Result}

\section{Subjects Characteristics Depending on Age}

The baseline characteristics of the subjects are summarized in Table 1 . The main symptom which was the main reason of undertaking HRIM is also described in Table 1. There were no statistical differences in symptoms among the 3 groups $(P=0.677)$. The 
Table 1. Baseline Characteristics Depending on Age

\begin{tabular}{|c|c|c|c|c|}
\hline & \multicolumn{3}{|c|}{ Age (yr) } & \multirow{2}{*}{$P$-value } \\
\hline & $<40$ & $40-65$ & $>65$ & \\
\hline Subjects (n [\%]) & $32(11.5)$ & $185(66.3)$ & $62(22.2)$ & \\
\hline Age (mean $\pm \mathrm{SD}, \mathrm{yr}$ ) & $30.4 \pm 7.0$ & $55.6 \pm 6.3$ & $73.0 \pm 4.5$ & \\
\hline \multicolumn{5}{|l|}{ Gender (n [\%]) } \\
\hline Male & $22(68.8)$ & $87(47.0)$ & $36(58.1)$ & 0.042 \\
\hline Female & $10(31.3)$ & $98(53.0)$ & $26(41.9)$ & \\
\hline Body weight (mean $\pm \mathrm{SD}, \mathrm{kg}$ ) & $62.5 \pm 18.7$ & $62.8 \pm 10.1$ & $62.7 \pm 9.8$ & 0.993 \\
\hline Height (mean $\pm \mathrm{SD}, \mathrm{cm})$ & $168.0 \pm 11.7$ & $163.0 \pm 8.5$ & $160 \pm 10.6$ & 0.029 \\
\hline $\mathrm{BMI}\left(\right.$ mean $\left.\pm \mathrm{SD}, \mathrm{kg} / \mathrm{m}^{2}\right)$ & $21.6 \pm 4.1$ & $24.1 \pm 4.9$ & $24.4 \pm 3.3$ & 0.111 \\
\hline Main symptoms (n [\%]) & & & & 0.677 \\
\hline Globus & $15(46.8)$ & $82(44.3)$ & $22(35.4)$ & \\
\hline Hoarseness & $0(0.0)$ & $6(3.2)$ & $4(6.4)$ & \\
\hline Cough & $2(6.2)$ & $11(5.9)$ & $1(1.6)$ & \\
\hline Voice change & $0(0.0)$ & $8(4.3)$ & $5(8.1)$ & \\
\hline Heartburn & $6(18.8)$ & $35(18.9)$ & $10(16.1)$ & \\
\hline Dysphagia & $1(3.1)$ & $11(5.9)$ & $5(8.1)$ & \\
\hline Sore throat & $3(9.4)$ & $21(11.6)$ & $7(11.2)$ & \\
\hline Dyspepsia & $2(6.3)$ & $8(4.3)$ & $5(8.1)$ & \\
\hline Respiratory difficulty & 1 & 2 & 0 & \\
\hline Hiatal hernia (n [\%]) & $2(6.9)$ & $33(18.1)$ & $9(15.3)$ & 0.305 \\
\hline \multicolumn{5}{|l|}{ Premedication } \\
\hline Opioid & $0(0.0)$ & $4(2.2)$ & $2(3.2)$ & 0.593 \\
\hline GI motor modulator & $4(12.5)$ & $14(7.6)$ & $6(9.7)$ & 0.618 \\
\hline
\end{tabular}

BMI, body mass index; GI, gastrointestinal.

proportion of males in Group A was significantly higher $(P=$ 0.039). In addition, the height of Group A $(170 \pm 10 \mathrm{~cm})$ was higher than that of Group B $(162 \pm 9 \mathrm{~cm})$, or that of Group C $(160 \pm 11 \mathrm{~cm})(P=0.005)$. Otherwise, there were no statistical differences in body weight and body mass index (BMI) among the 3 groups. There were opioid premedication histories within 1 week before HRIM test in 6 subjects, and gastrointestinal motor modulators in 24 subjects, but there were no statistical differences in symptoms among the 3 groups $(P=0.593$ and $P=0.618)$.

\section{High-resolution Impedance Manometry}

The HRIM results of 3 groups are summarized in Table 2. The basal UES pressure in the Group $\mathrm{C}$ was lower than those of the Group A and Group B (Fig. 2 and Table 2). There was no significant difference in values related with LES including hiatal hernia $(P=0.305)$ among the 3 groups. Group C (3.4 \pm 0.9 seconds) had a significantly longer duration distal contractile duration (on position 3 ) than those of the Group A (2.7 \pm 0.3 seconds, $P=$ $0.001)$. Group C $(85.8 \pm 34.1 \mathrm{mmHg})$ had a significantly lower distal contractile amplitude (on position 4; Fig. 1) than those of the
Group B (105.1 $\pm 40.5 \mathrm{mmHg}, P=0.005)$ (Fig. 2). There was no significant difference among the 3 groups in UES coordination results. Goup C had significantly slower CFV $(3.6 \pm 1.1 \mathrm{~cm} / \mathrm{sec})$ and onset velocity $(3.7 \pm 1.5 \mathrm{~cm} / \mathrm{sec})$ than those of the Group A $(4.4 \pm 1.3 \mathrm{~cm} / \mathrm{sec}, P=0.015$ and $4.7 \pm 2.0 \mathrm{~cm} / \mathrm{sec}, P=0.040)$. Group C (1248.8 $\pm 939.7 \mathrm{mmHg} \cdot \mathrm{sec} \cdot \mathrm{cm})$ had significantly lower DCI than those of Group B $\left(1460.2 \pm 968.9 \mathrm{mmHg} \cdot \mathrm{sec}^{\cdot} \mathrm{cm}, P\right.$ $=0.020)$. There was no significant difference among the 3 groups in the impedance test. One hundred and eight subjects were diagnosed as ineffective esophageal motility according to the 3.0 Chicago classification of esophageal motility and there were no differences between the 3 groups $(P=0.554)$.

\section{Discussion}

In our analysis using HRIM, there were differences of esophageal motility in aged people. However, it was not a kind of fundamental change that did not provoke esophageal symptoms in the aged population. Actually, many studies have shown that esophageal motility deteriorates with age. Nishimura et $\mathrm{al}^{20}$ reported that esoph- 
Table 2. High-resolution Esophageal Impedance Manometric Findings Depending on Age

\begin{tabular}{|c|c|c|c|c|}
\hline & \multicolumn{3}{|c|}{ Age (yr) } & \multirow{2}{*}{$P$-value } \\
\hline & $<40$ & $40-65$ & $>65$ & \\
\hline \multicolumn{5}{|l|}{ Upper esophageal sphincter (UES) } \\
\hline Location, distal $(\mathrm{cm})$ & $22.2 \pm 1.2$ & $22.1 \pm 1.2$ & $22.0 \pm 1.5$ & 0.745 \\
\hline Location, proximal $(\mathrm{cm})$ & $20.1 \pm 1.3$ & $20.1 \pm 1.2$ & $20.2 \pm 1.5$ & 0.734 \\
\hline Length (cm) & $2.1 \pm 0.3$ & $2.1 \pm 0.4$ & $2.0 \pm 0.4$ & 0.348 \\
\hline UES pressure (mild respiration) $(\mathrm{mmHg})$ & $92.7 \pm 46.0$ & $92.5 \pm 49.0$ & $63.8 \pm 32.2$ & $<0.001$ \\
\hline \multicolumn{5}{|l|}{ Lower esophageal sphincter (LES) } \\
\hline Location, distal $(\mathrm{cm})$ & $46.8 \pm 2.9$ & $45.8 \pm 2.6$ & $45.6 \pm 2.9$ & 0.171 \\
\hline Location, proximal $(\mathrm{cm})$ & $44.4 \pm 3.0$ & $43.5 \pm 2.5$ & $43.5 \pm 3.1$ & 0.235 \\
\hline Length $(\mathrm{cm})$ & $2.3 \pm 0.4$ & $2.4 \pm 1.3$ & $2.3 \pm 0.4$ & 0.799 \\
\hline LES pressure (mild respiration) (mmHg) & $21.5 \pm 12.2$ & $20.4 \pm 11.2$ & $20.6 \pm 11.3$ & 0.898 \\
\hline IEM (The 3.0 Chicago classification) & $15(46.9)$ & $71(38.4)$ & $22(35.5)$ & 0.554 \\
\hline IRP (mmHg) & $8.6 \pm 4.4$ & $10.9 \pm 6.3$ & $10.4 \pm 5.2$ & 0.140 \\
\hline $\mathrm{DCI}(\mathrm{mmHg} \cdot \mathrm{sec} \cdot \mathrm{cm})$ & $1023.1 \pm 787.3$ & $1460.2 \pm 968.9$ & $1248.8 \pm 939.7$ & 0.037 \\
\hline $\mathrm{CFV}(\mathrm{cm} / \mathrm{sec})$ & $4.4 \pm 1.3$ & $4.0 \pm 1.3$ & $3.6 \pm 1.1$ & 0.015 \\
\hline Onset velocity $(\mathrm{cm} / \mathrm{sec})$ & $4.7 \pm 2.0$ & $4.1 \pm 1.9$ & $3.7 \pm 1.5$ & 0.040 \\
\hline Pharyngeal peak pressure $(\mathrm{mmHg})$ & $175.5 \pm 77.0$ & $187.3 \pm 102.6$ & $185.0 \pm 88.3$ & 0.831 \\
\hline $\mathrm{DL}(\mathrm{sec})$ & $6.7 \pm 1.1$ & $6.3 \pm 1.2$ & $6.1 \pm 1.2$ & 0.157 \\
\hline
\end{tabular}

IEM, ineffective esophageal motility; IRP, integrated relaxation pressure; DCI, distal contractile integral; CFV, contractile front velocity; DL, distal latency.
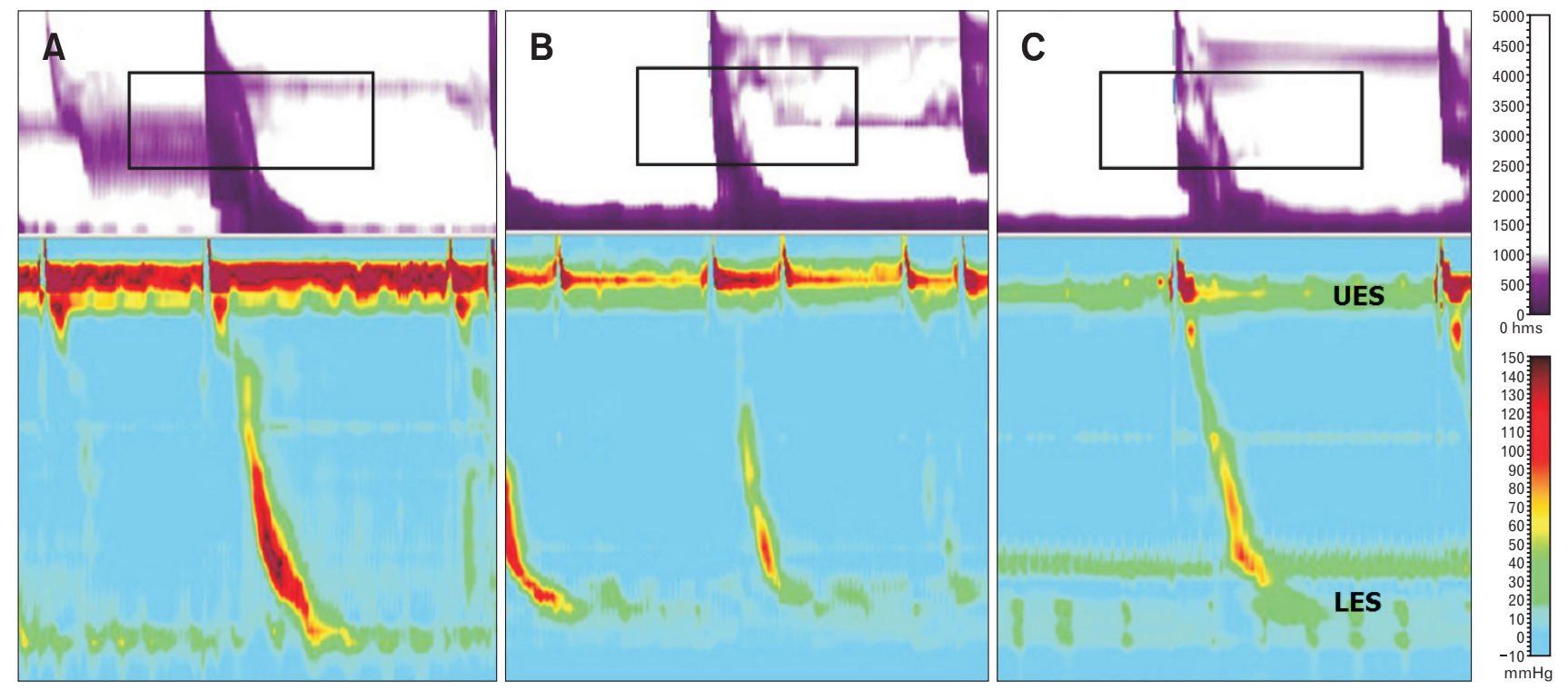

Figure 2. Comparison of high-resolution esophageal impedance manometry depending on age. The basal upper esophageal sphincter (UES) pressure in the age group above 65 years old (C) was lower than those of age below 40 years old (A) and 40-65 years old group (B). In addition, the aged group above 65 years old (C) showed lower distal contractile amplitude than the 40-65 years old group (B). LES, lower esophageal sphincter.

ageal transmission sequence of peristalsis and contractility of the esophageal body are reduced in aged people. Resting LES pressure had the tendency to decrease, but not statistically significant, and peristaltic contraction amplitude was lower than that of the group aged under 49 years compared to the group aged over 70 years on analysis using conventional esophageal manometry. ${ }^{20}$ Ferriolli et al ${ }^{21}$ reported that impaired clearance of refluxed materials associated with defective esophageal peristalsis was found more frequently in 
aged subjects on analysis using conventional esophageal manometry. Our results on analysis using HRIM were consistent with those of earlier studies on analysis using conventional manometry, suggesting that there are the disturbances of esophageal peristalsis in aged people.

The peristalsis of the esophagus is performed by coordinated contraction of its muscular lining led by stimuli from the nerve plexus situated in its muscularis proper. ${ }^{22-24}$ In the muscularis proper striated muscle and smooth muscle, the cells are regionally distributed. Proximal part of esophagus is built from the striated muscle cells only, but along the length of the esophagus smooth muscle cells are gradually replacing them. ${ }^{25}$ In our analysis, the contractile amplitude of the distal esophagus was lower in the aged group $(P$ $=0.005)$ and the contractile duration of the distal esophagus was longer in the aged group $(P=0.001)$, which might be a compensation change. Actually these results support different effects of aging on proximal and distal esophageal motility. Probably, these results might be related with the differences of muscle types between the proximal and distal parts of the esophagus. The changes of esophageal motility in the aged population are more frequently seen in the distal part of esophageal body. ${ }^{26}$ In addition, a study showed that lower esophageal sphincter (LES) relaxation was reduced and distal contractile integral was higher with liquid swallows in asymptomatic older individuals. ${ }^{27}$

The UES is a high pressure zone comprising of functional activity of the inferior pharyngeal constrictor, cricopharyngeus, and cranial cervical esophagus, together with cartilage and connective tissue. The cricopharyngeus is the most important muscle, and neural connections that have been identified are the recurrent laryngeal nerve from below and a pharyngeal plexus from above. The role of the UES is to prevent entry of air into the digestive tract, to prevent the reflux of material from the esophagus into the pharynx when swallowing, and to allow the release of intraesophageal material when belching or vomiting. ${ }^{28-32}$ Effects of aging on UES contraction are not certain so far. There was a report that a significant inverse relation was found between age and resting UES pressure, and time from peak of pharyngeal contraction to UES nadir in 10 healthy elderly was significantly shorter than those of 10 younger adults using conventional manometry. ${ }^{33}$ However, another report suggested no difference between a healthy elderly group and a healthy younger group in amplitude or area under the curve of proximal esophageal contractions in the study using conventional manometry. ${ }^{34}$ Wilson et $\mathrm{al}^{35}$ reported that healthy older subjects were found to have only marginally lower UES tonic pressures in the study using conventional manometry. However, all of these re- ports used conventional manometry, which might be a cause of diverse results. The utility of conventional manometry for evaluating pharyngeal swallowing is limited, because of asymmetry and deglutitive movements of the oropharyngeal structures. ${ }^{36}$ In our analysis using HRIM, which has a strong point in evaluating pharyngeal swallowing, the basal UES pressure was lower in the aged group above 65 years old $(P<0.001)$. However, there was no significant difference among the 3 groups in UES coordination including time duration from pharyngeal contraction to UES relaxation and UES opening duration. Several studies showed that the function of UES could be related to air swallowing, belching, vomiting, and aspiration pneumonia in aged people. ${ }^{37-39}$

Some controversy has existed concerning the effect of age on LES function. In addition, differences in research topics might exist between the East and the West in the field of neurogastroenterology and motility. ${ }^{40}$ In our analysis, there was no significant difference in LES pressure depending on age. This finding is comparable to a previous report which showed no difference in the LES pressure between the group of healthy subjects aged under 45 years old and those aged over 65 years old in a study using esophageal manometry carried out with a 21-channel manometric assembly. ${ }^{41}$ In contrast, in a study using high-resolution manometry, 19 patients aged over 80 years old ( $85 \pm 0.7$ years old $)$ with dysphagia had higher basal lower esophageal sphincter pressures than 19 younger patients (32 \pm 1.7 years old) with dysphagia using high-resolution manometry. ${ }^{26}$ In a study of 95 healthy subjects, both the distal esophageal contractile amplitude and duration significantly increased with age. ${ }^{42}$ In another study, basal LES pressures were lower in younger patients (17-46 years old) than older patients (80-93 years old). ${ }^{43}$ Several studies showed that esophageal distensibilities are decreased and LES pressures are higher in aged subjects. ${ }^{5,4-46}$ However, basal LES pressures of the older group was not higher than that of the younger group which needs explanation regarding age definition or characteristics of the aged group. In the present study the definition of the aged group were subjects over 65 years old, which is lower than that of previously published papers. That is, the definition of the elderly group were subjects over 70 years old ${ }^{45,46}$ or over 80 years old. ${ }^{26,43}$ Another difference is that the present study enrolled heterogeneous numbers in each group. The enrolled number in Group C (over 65 years old, $\mathrm{n}=62$ ) was less than Group B (40-65 years old, $\mathrm{n}=185$ ).

In the present study, there were inverse correlations with height and IRP values $(r=-0.297, P=0.001)$, body weight and IRP values $(r=-0.241, P=0.008)$, height and $\mathrm{DCI}$ values $(r=-0.215, P=0.021)$, and body weight and CFV values $(r=$ 
$-0.198, P=0.033)$. Also, there was linear correlation with height and DL values $(r=0.314, P=0.005)$. There was no correlation with BMI and parameters of the Chicago classification of esophageal motility. Recently published studies showed the correlation with esophageal motility and body weight, height, BMI. Study by Tanaka et $\mathrm{al}^{47}$ described that there was inverse correlation with BMI and DCI, total cholesterol and DCI, BMI, and IRP. Also body weight, height, BMI could be predictive factors of esophageal motility. $^{47}$

The limitation of the present study is that almost all subjects were symptomatic although there was no major esophageal motility disorder according to the 3.0 Chicago classification of esophageal motility. Initially we planned to perform this study in age matched normal subjects. However, we found it was impossible to find an adequate number of subjects. Thus we chose subjects who received HRIM with mild symptoms, suggestive of normal people.

In spite of these limitations our results suggest that the decrease of UES pressure, distal esophageal motility, and peristaltic velocity might be related with esophageal symptoms in the aged population. These suggestions using HRIM may be specific values for gastroenterologists and for esophageal surgeons specializing in benign pathologies like esophageal motor disorders and for medical personnel working in geriatric medicine.

Financial support: This work was supported by a National Research Foundation of Korea (NRF) grant for the Global Core Research Center (GCRC) funded by the Korea government (MSIP) (Grant No. 2011-0030001).

\section{Conflict of Interest: None.}

Author contributions: Young Kwang Shim analyzed and interpreted the data, and wrote a manuscript; Nayoung Kim designed, organized, and mediated the present study, and supervised the manuscript; Yo Han Park, Jong-Chan Lee, Jihee Sung, Yoon Jin Choi, and Hyuk Yoon collected the data and interpretation of the data; and Cheol Min Shin, Young Soo Park, and Dong Ho Lee advised design, supported preparing manuscript including tables and the figures, and supervised the manuscript.

\section{References}

1. Steele CM, Greenwood C, Ens I, Robertson C, Seidman-Carlson R. Mealtime difficulties in a home for the aged: not just dysphagia. Dysphagia 1997;12:43-50; discussion 51 .
2. Cook IJ. Oropharyngeal dysphagia. Gastroenterol Clin North Am 2009;38:411-431.

3. Humbert IA, Robbins J. Dysphagia in the elderly. Phys Med Rehabil Clin N Am 2008;19:853-866, ix-x.

4. Grande L, Lacima G, Ros E, et al. Deterioration of esophageal motility with age: a manometric study of 79 healthy subjects. Am J Gastroenterol 1999;94:1795-1801.

5. Gregersen H, Pedersen J, Drewes AM. Deterioration of muscle function in the human esophagus with age. Dig Dis Sci 2008;53:3065-3070.

6. Ren J, Shaker R, Kusano M, et al. Effect of aging on the secondary esophageal peristalsis: presbyesophagus revisited. Am J Physiol 1995;268(5 Pt 1):G772-G779.

7. Saffrey MJ. Ageing of the enteric nervous system. Mech Ageing Dev 2004;125:899-906.

8. Lee JY, Kim N, Kim SE, et al. Clinical characteristics and treatment outcomes of 3 subtypes of achalasia according to the Chicago classification in a tertiary institute in Korea. J Neurogastroenterol Motil 2013;19:485494.

9. Wade PR, Cowen T. Neurodegeneration: a key factor in the ageing gut. Neurogastroenterol Motil 2004;16(suppl 1):19-23.

10. Meciano Filho J, Carvalho VC, de Souza RR. Nerve cell loss in the myenteric plexus of the human esophagus in relation to age: a preliminary investigation. Gerontology 1995;41:18-21.

11. Eckardt VF, LeCompte PM. Esophageal ganglia and smooth muscle in the elderly. Am J Dig Dis 1978;23:443-448

12. Tack J, Vantrappen G. The aging oesophagus. Gut 1997;41:422-424.

13. Eslick GD, Talley NJ. Dysphagia: epidemiology, risk factors and impact on quality of life--a population-based study. Aliment Pharmacol Ther 2008;27:971-979.

14. Kallmünzer B, Sörensen B, Neuhuber WL, Wörl J. Enteric co-innervation of striated muscle fibres in human esophagus. Neurogastroenterol Motil 2008;20:597-610

15. Wang A, Pleskow DK, Banerjee S, et al. Esophageal function testing. Gastrointest Endosc 2012;76:231-243.

16. Mittal RK, Frank E, Lange RC, McCallum RW. Effects of morphine and naloxone on esophageal motility and gastric emptying in man. Dig Dis Sci 1986;31:936-942.

17. Kahrilas PJ, Ghosh SK, Pandolfino JE. Esophageal motility disorders in terms of pressure topography: the Chicago Classification. J Clin Gastroenterol 2008;42:627-635.

18. Pandolfino JE, Ghosh SK, Rice J, Clarke JO, Kwiatek MA, Kahrilas PJ. Classifying esophageal motility by pressure topography characteristics: a study of 400 patients and 75 controls. Am J Gastroenterol 2008;103:2737.

19. Pandolfino JE, Fox MR, Bredenoord AJ, Kahrilas PJ. High-resolution manometry in clinical practice: utilizing pressure topography to classify oesophageal motility abnormalities. Neurogastroenterol Motil 2009;21:796-806

20. Nishimura N, Hongo M, Yamada M, et al. Effect of aging on the esophageal motor functions. J Smooth Muscle Res 1996;32:43-50.

21. Ferriolli E, Oliveira RB, Matsuda NM, Braga FJ, Dantas RO. Aging, esophageal motility, and gastroesophageal reflux. J Am Geriatr Soc 
1998;46:1534-1537.

22. Bruder E, Rougemont AL, Furlano RI, et al. [Motility disorders of the esophagus]. Pathologe 2013;34:118-132.[German]

23. Gutschow CA, Leers JM, Schröder W, et al. Effect of aging on esophageal motility in patients with and without GERD. Ger Med Sci 2011;9:Doc22.

24. Kallmünzer B, Sörensen B, Neuhuber WL, Wörl J. Enteric co-innervation of striated muscle fibres in human oesophagus. Neurogastroenterol Motil 2008;20:597-610.

25. Liebermann-Meffert D, Geissdörfer K. Is the transition of striated into smooth muscle precisely known? In: Giuli R, McCallum RW, Skinner DB, eds. Primary motility disorders of the esophagus. Paris, Londres, Rome: John Libbey Eurotext 1991:108-112.

26. Besanko LK, Burgstad CM, Mountifield R, et al. Lower esophageal sphincter relaxation is impaired in older patients with dysphagia. World $\mathrm{J}$ Gastroenterol 2011;17:1326-1331.

27. Besanko LK, Burgstad CM, Cock C, Heddle R, Fraser A, Fraser RJ. Changes in esophageal and lower esophageal sphincter motility with healthy aging. J Gastrointestin Liver Dis 2014;23:243-248.

28. Asoh R, Goyal RK. Manometry and electromyography of the upper esophageal sphincter in the opossum. Gastroenterology 1978;74:514520 .

29. Cook IJ, Dodds WJ, Dantas R, et al. Opening mechanisms of the human upper esophageal sphincter. American Journal of PhysiologyGastrointestinal and Liver Physiology 1989;257:G748-G759.

30. Gerhardt D, Hewett J, Moeschberger M, Shuck T, Winship D. Human upper esophageal sphincter pressure profile. Am J Physiol 1980;239:G49-G52.

31. Lang I, Dantas R, Cook I, Dodds W. Videoradiographic, manometric, and electromyographic analysis of canine upper esophageal sphincter. Am J Physiol 1991;260(6 Pt 1):G911-G919.

32. Nilsson M, Isberg A, Schiratzki H. The location of the upper oesophageal sphincter and its behaviour during bolus propagation-a simultaneous cineradiographic and manometric investigation. Clin Otolaryngol Allied Sci 1989;14:61-65.

33. Fulp SR, Dalton CB, Castell JA, Castell DO. Aging-related alterations in human upper esophageal sphincter function. Am J Gastroenterol 1990;85:1569-1572.

34. Dantas RO, Alves LM, Dalmazo J, Santos CM, Cassiani Rde A, Nasci- mento WV. Effect of age on proximal esophageal response to swallowing. Arq Gastroenterol 2010;47:339-343.

35. Wilson JA, Pryde A, Macintyre CC, Maran AG, Heading RC. The effects of age, sex, and smoking on normal pharyngoesophageal motility. Am J Gastroenterol 1990;85:686-691.

36. Kahrilas PJ, Sifrim D. High-resolution manometry and impedance-pH/ manometry: valuable tools in clinical and investigational esophagology. Gastroenterology 2008;135:756-769.

37. Kim Y, Park T, Oommen E, McCullough G. Upper esophageal sphincter opening during swallow in stroke survivors. Am J Phys Med Rehabil 2015;94:734-739.

38. Mu L, Sobotka S, Chen J, et al. Altered pharyngeal muscles in Parkinson disease. J Neuropathol Exp Neurol 2012;71:520-530.

39. Rofes L, Clavé P, Ouyang A, et al. Neurogenic [corrected] and oropharyngeal dysphagia. Ann N Y Acad Sci 2013;1300:1-10.

40. Lee JY, Kim N, Kim GH, Kim GH. Comparing the Areas of Interest in the Field of Functional Gastrointestinal Disorder and Neurogastroenterology and Motility Between the East and the West. J Neurogastroenterol Motil 2015;21:503-510.

41. Kawami N, Iwakiri K, Sano H, Tanaka Y, Sakamoto C. Effects of aging and acid reflux on esophageal motility. Digestion 2015;91:181-186.

42. Richter JE, Wu WC, Johns DN, et al. Esophageal manometry in 95 healthy adult volunteers. Dig Dis Sci 1987;32:583-592.

43. Andrews JM, Fraser RJ, Heddle R, Hebbard G, Checklin H. Is esophageal dysphagia in the extreme elderly ( $>$ or $=80$ years) different to dysphagia younger adults? A clinical motility service audit. Dis Esophagus 2008;21:656-659.

44. Rao SS, Mudipalli RS, Mujica VR, Patel RS, Zimmerman B. Effects of gender and age on esophageal biomechanical properties and sensation. Am J Gastroenterol 2003;98:1688-1695.

45. Hashemi N, Banwait KS, DiMarino AJ, Cohen S. Manometric evaluation of achalasia in the elderly. Aliment Pharmacol Ther 2005;21:431434.

46. Chuah SK, Changchien CS, Wu KL, et al. Esophageal motility differences among aged patients with achalasia: a Taiwan report. J Gastroenterol Hepatol 2007;22:1737-1740.

47. Tanaka Y, Ihara E, Nakamura K, et al. Clinical characteristics associated with esophageal motility function. J Gastroenterol Hepatol 2016;31:11331140 . 